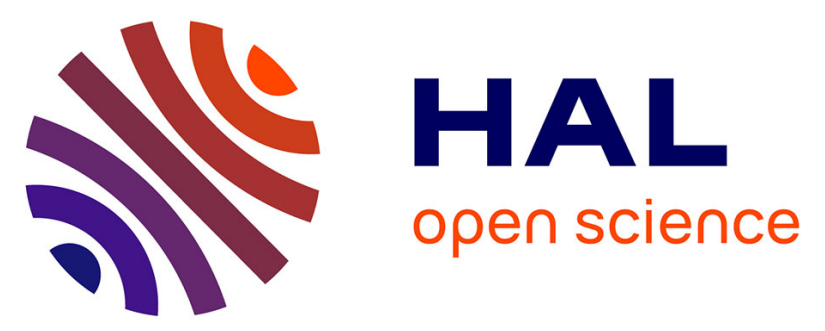

\title{
Immature stages and male Paraseiulus amacroporus Faraji et al., (Acari: Mesostigmata: Phytoseiidae) from Southwestern Iran
}

Bahman Asali Fayaz, Mohammad Khanjani, Samira Bakhshi, Edward A. Ueckermann

\section{To cite this version:}

Bahman Asali Fayaz, Mohammad Khanjani, Samira Bakhshi, Edward A. Ueckermann. Immature stages and male Paraseiulus amacroporus Faraji et al., (Acari: Mesostigmata: Phytoseiidae) from Southwestern Iran. Acarologia, 2017, 57 (4), pp.869-876. 10.24349/acarologia/20174201 . hal01598401

\section{HAL Id: hal-01598401 \\ https://hal.science/hal-01598401}

Submitted on 29 Sep 2017

HAL is a multi-disciplinary open access archive for the deposit and dissemination of scientific research documents, whether they are published or not. The documents may come from teaching and research institutions in France or abroad, or from public or private research centers.
L'archive ouverte pluridisciplinaire HAL, est destinée au dépôt et à la diffusion de documents scientifiques de niveau recherche, publiés ou non, émanant des établissements d'enseignement et de recherche français ou étrangers, des laboratoires publics ou privés.

\section{()ㅜ) $\Theta$}

Distributed under a Creative Commons Attribution - NoDerivatives| 4.0 International 


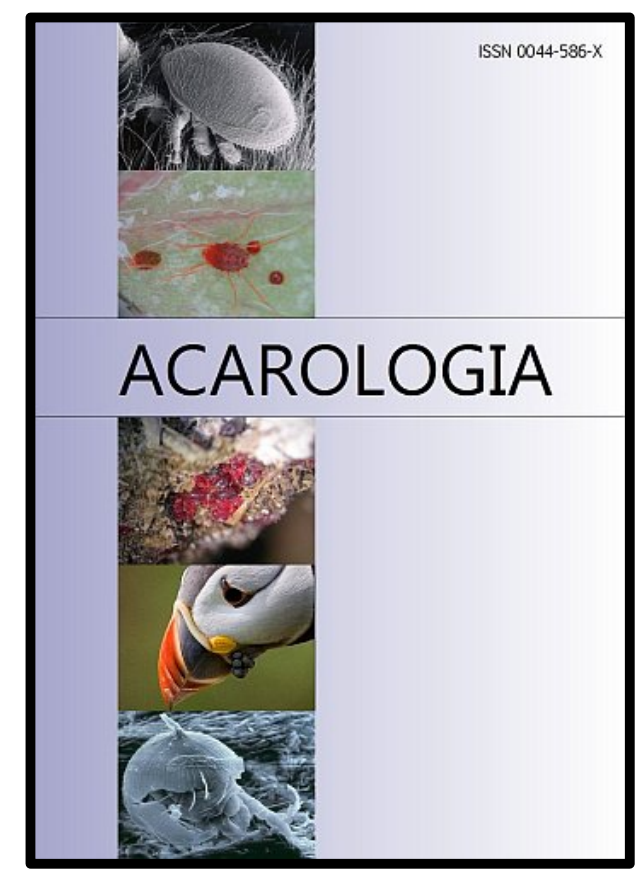

\section{ACAROLOGIA}

A quarterly journal of acarology, since 1959

Publishing on all aspects of the Acari

All information:

http://www1.montpellier.inra.fr/CBGP/acarologia/ acarologia@supagro.inra.fr

\section{OPEN ACCESS}

\section{Acarologia is proudly non-profit, with no page charges and free open access}

Please help us maintain this system by encouraging your institutes to subscribe to the print version of the journal and by sending us your high quality research on the Acari.

Subscriptions: Year 2017 (Volume 57): $380 €$ http://www1.montpellier.inra.fr/CBGP/acarologia/subscribe.php

Previous volumes (2010-2015): $250 € /$ year (4 issues)

Acarologia, CBGP, CS 30016, 34988 MONTFERRIER-sur-LEZ Cedex, France

The digitalization of Acarologia papers prior to 2000 was supported by Agropolis Fondation under the reference ID 1500-024 through the « Investissements d'avenir » programme

(Labex Agro: ANR-10-LABX-0001-01)
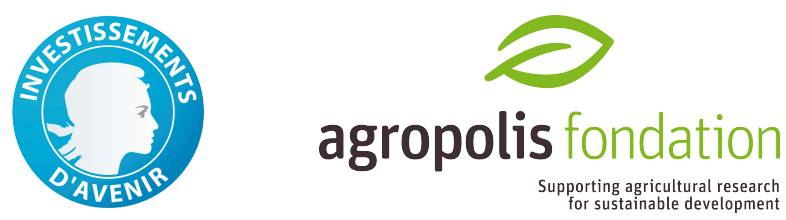

Acarologia is under free license and distributed under the terms of the

Creative Commons-BY-NC-ND which permits unrestricted non-commercial use, distribution, and reproduction in any medium, provided the original author and source are credited. 


\title{
Immature stages and male Paraseiulus amacroporus Faraji et al., (Acari: Mesostigmata: Phytoseiidae) from Southwestern Iran
}

\author{
Bahman ASAli FAYAZ ${ }^{1}$, Mohammad KHANJANI ${ }^{1 凶}$, Samira BAKHSHI ${ }^{1}$ and Edward A. UECKERMANN ${ }^{2}$ \\ (Received 09 February 2017; accepted 26 April 2017; published online 04 July 2017; edited by Serge KREITER) \\ ${ }^{1}$ Department of Plant Protection, College of Agriculture, Bu-Ali Sina University, Hamedan, Iran. basalifayaz@gmail.com, \\ (凶)mkhanjani@gmail.com,samirabakhshi92@gmail.com \\ ${ }^{2}$ Unit for Environmental Sciences and Management, Potchefstroom Campus, North-West University, Private Bag X6001, Potchefstroom, 2520, \\ South Africa.edalbert@lantic.net
}

\begin{abstract}
This study presents the morphological characteristics of immature and adult male stages of Paraseiulus amacroporus Faraji, Jalaeian and McMurtry, 2008 (Phytoseiidae) collected from pistachio trees, Pistacia atlantica Desf. (Anacardiaceae), Shiraz vicinity (Fars province), South west Iran. The genders of the deutonymphal stage can be determined by the number of paired setae in the opisthogaster (six in female vs. four in male).
\end{abstract}

KEYWORDS - mite; Typhlodrominae; Paraseiulini; predator; pistachio

ZOOBANK — EB9AE57E-2FB9-4BDB-8BF9-44D664550B93

\section{INTRODUCTION}

The Paraseiulini (subfamily Typhlodrominae) consisted of three genera (Paraseiulus Muma, Australiseiulus Muma and Kuzinellus Wainstein). The genus Paraseiulus is distinguished by absence of opisthogastric setae JV2 and ventrianal shield soleshaped with two pairs of preanal setae and without pores (Chant and McMurtry, 1994). To date 15 valid species (plus seven junior synonymy species) have been describes and recorded from Eurasia, Africa and America continents (according to Demite et al. 2017) and ranks second in the tribe. According to McMurtry et al. (2013), representatives of Paraseiulus are categorized as specialized predators of tydeoids (Tydeoidea) (Subtype I-c, lifestyle). Paraseiulus amacroporus Faraji, Jalaeian and McMurtry, 2008 was described and collected from pistachio trees, Borkhar (Isfahan Province), Iran. In this paper the immature and adult stages [protonymph, deutonymph ( $\circ \& \sigma^{7}$ ) and male] are described and illustrated.

\section{MATERIALS AND METHODS}

The specimens were collected from leaves of pistachio trees, Pistacia atlantica Desf. (Anacardiaceae), Shiraz region, (Fars province), Southwestern Iran, under a stereomicroscope (Wild $\mathrm{M}^{\circledR}{ }^{\circledR}$ ). The mites were mounted on microscope slides in Hoyer's medium for examination under an Olympus BX51 phase and differential interference contrast microscope. Illustrations were done with the aid of a camera Lucida apparatus attached to the microscope and measurements were done with a graded ocu- 

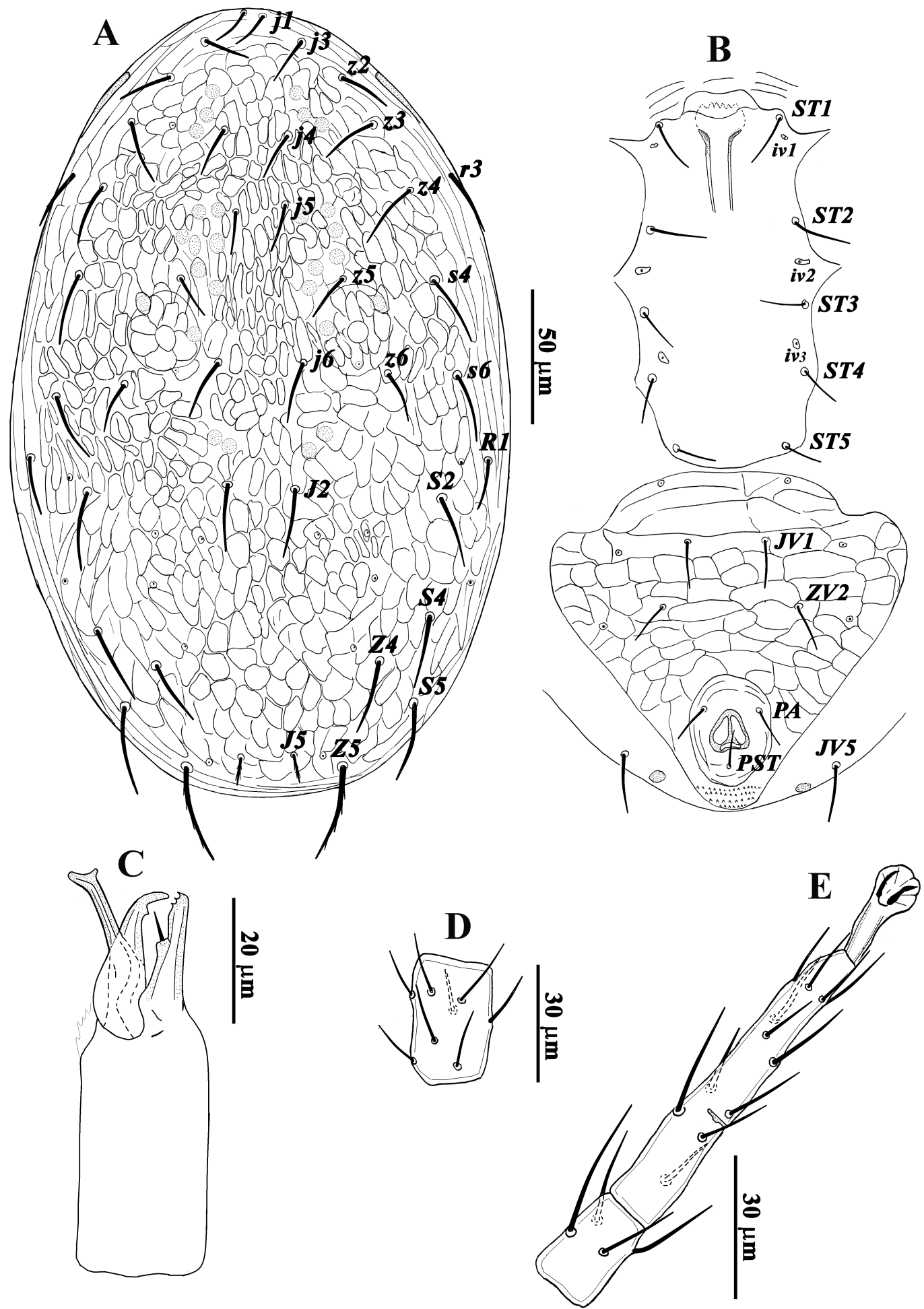

FIgURE 1: Paraseiulus amacroporus Faraji et al. (Adult male): A - Dorsal view of idiosoma; B - Ventral view of idiosoma; C - Chelicera; D - Genu II; E - Basitarsus IV. 

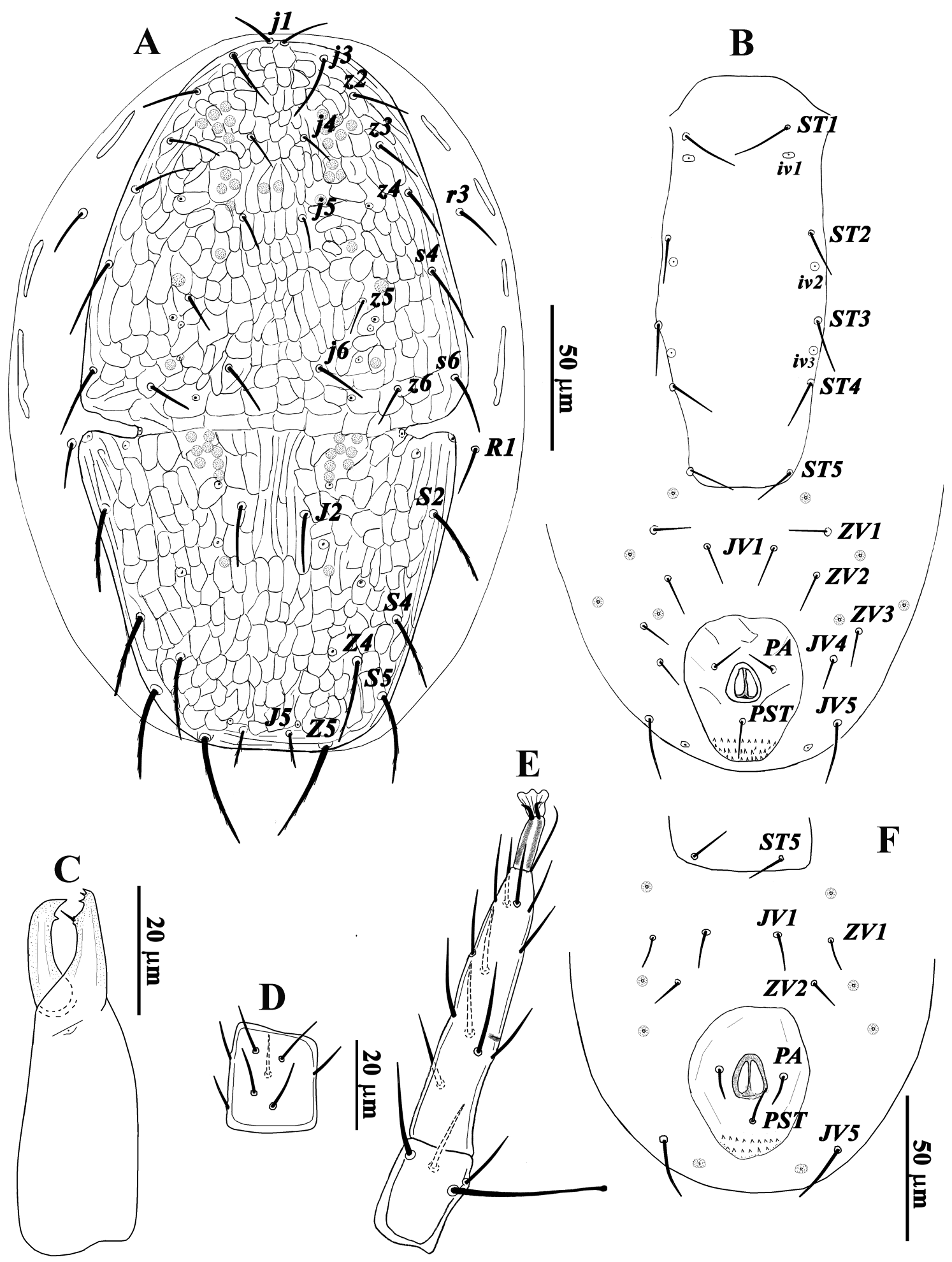

FIgURe 2: Paraseiulus amacroporus Faraji et al. (Deutonymph) A - Dorsal view of idiosoma (†); B - Ventral view of idiosoma (९); C Chelicera (o)); D - Genu II (ㅇ); E - Basitarsus IV (o); F - Ventral view of idiosoma (ơ) 
lar. Measurements are given in micrometers. Leg lengths do not include pretarsus. The classification system used follows that of Chant \& McMurtry (2007). The setal notations used follow Lindquist and Evans (1965) as adapted by Rowell et al. (1978) and also Rowell \& Chant (1979) to phytoseiid mites; dorsal and ventral setal patterns are according to Chant and Yoshida-Shaul (1989 and 1991); organotaxy follows Athias-Henriot (1975).

\section{RESULTS}

Phytoseiidae Berlese, 1916: 33.

Typhlodrominae Wainstein, 1962: 131;

Chant and McMurtry, 1994: 235.

Paraseiulini Wainstein, 1976: 697-698.

Paraseiulus Muma, 1961: 299.

\section{Paraseiulus amacroporus}

Faraji, Jalaeian and McMurtry, 2008: 65.

Diagnosis (female) - Dorsal shield without setae Z3 and solenostomes (prominent pores), with distinct small pores, peritremes extending to level of, or just passing, the bases of setae $z 2$, calyx of spermatheca saccular, without neck and with a Cshaped atrium, fixed digit of chelicera with two subapical teeth (Faraji et al. 2008).

\section{Female}

(See Faraji et al. 2008).

\section{Male}

(Figure 1) $(\mathrm{n}=5)$

Idiosoma oval; setal pattern: 13A:8A/10: JV-2, 3, 4: ZV-I,3. All idiosomal and leg setae smooth, except Z5 and J5, barbed.

Dorsum (Fig. 1A) - Dorsal shield reticulated, 260 - 280 long, 170 - 190 wide at level of R1, with 21 pairs of setae and 10 pairs of poroids and solenostomes (prominent pores) absent. Length of setae: $j 1$ $11-13, j 314-16, j 415-16, j 515-17, j 620-22, J 2$ $21-23, J 511-13, z 220-21, z 321-23, z 423-25$, $z 514-16, z 615-17, Z 424-26$, Z5 $36-38, s 423-$ 25 , s6 $24-27$, s2 $23-25, S 423-26$, S5 $27-30$, r3 20 $-23, R 119-21$.
Venter (Fig. 1B) - Sternogenital shield smooth, 125 - 130 long, anterior and posterior margins convex; five pairs of setae subequal in length ( ST1 18 - 20, ST2 17 - 18, ST3 17 - 18, ST4 17 - 19, ST5 $17-18$ ); three pairs of poroids (iv1-iv3). Ventrianal shield reticulated, subtriangular; anterior margin concave, 113 - 118 long and 120 - 132 wide at level of setae $J V 1$; two pairs of pre-anal setae ( $J V 1$ and $Z V 2$ ); three pairs of poroids; no preanal pores. Opisthogastric cuticle with one pair of setae ( JV5) and one pair of poroids. Length of opisthogastric setae: JV1 14 - 15, JV5 20 - 21, ZV2 15, PA 13 - 14 and PST $14-15$.

Peritreme (Fig. 1A) - Extending to level of setae z2, 105 - 112 long.

Chelicera (Fig. 1C) - Chelicera 79 - 83 long; fixed digit 16 - 17 long, with two subapical teeth; pilus dentilis 3 long; movable digit $16-18$ long and with one tooth, shaft of spermadactyl 9-11 long, arched and heel shaped distally, 4 long.

Legs I-IV (Figs. 1D-E) — Lengths: 228 - 235, 200 $-215,220-225,280-300$, respectively. Genu II with eight setae (2 2/1 2/0 1); Basitarsus IV with a pointed macroseta, $25-30$ long.

\section{Deutonymph (female)}

(Figure 2) $(\mathrm{n}=6)$

Idiosoma oval. All idiosomal and leg setae smooth, except S2, S4, S5, Z4, Z5 and J5 barbed.

Dorsum (Fig. 2A) - Dorsal shield reticulated, with mediolateral incisions, 265 - 270 long, 140 150 wide at level of setae $R 1$, with 19 pairs of setae, 13 pairs of poroids and solenostomes (prominent pores) absent. Length of setae: $j 113-15, j 320$ - 21, j4 13 - 15, j5 12 - 14, j6 20, J2 19 - 22, J5 11 - 13, $z 219-20, z 318-19, z 420-23, z 513-15, z 613-15$, Z4 30 - 33, Z5 34 - 36, s4 25 - 26, s6 22 - 25, S2 29 31, S4 30, S5 31 - 33, r3 17 - 19, R1 18 - 20.

Venter (Fig. 2B) - Sternal shield smooth, anterior margin convex, with five pairs of setae subequal in length (ST1 18 - 21, ST2 $19-20$, ST3 18 19 , ST4 $17-18$, ST5 $17-18$ ), three pairs of poroids (iv1-iv3). Opisthogastric cuticle with six pairs of setae $(J V 1, J V 4, J V 5, Z V 1, Z V 2, Z V 3)$ and five pairs of poroids. Length of opisthogastric setae: JV1 $14-16$, 


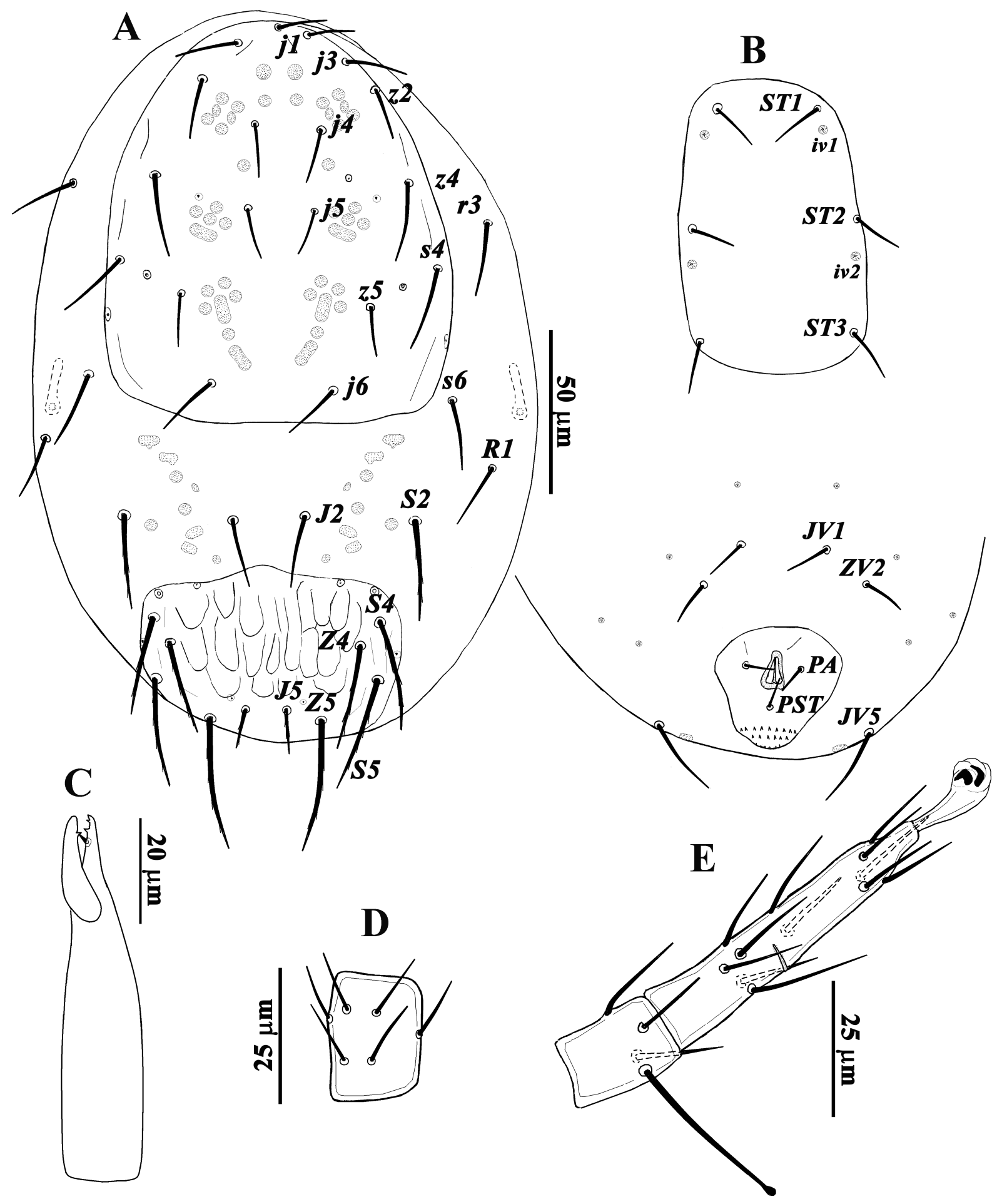

FIgURE 3: Paraseiulus amacroporus Faraji et al. (Protonymph): A - Dorsal view of idiosoma; B - Ventral view of idiosoma; C - Chelicera; D - Genu II; E - Basitarsus IV. 
JV4 11 - 13, JV5 22 - 25, ZV1 14 - 15, ZV2 12 - 14, ZV3 10 - 12, PA 12 - 13, PST 13 - 14.

Peritreme (Fig. 2A) - Incomplete, fragmented.

Chelicera (Fig. 2C) - Chelicera 84 - 95 long; fixed digit 17 - 19 long, with two subapical teeth; pilus dentilis 3-4 long; movable digit 16-18 long and with one tooth.

Legs I-IV (Figs. 2D-E) - Lengths: 260 - 270, 215 - 235, 225 - 235, $280-310$, respectively. Genu IV with eight setae (2 2/1 2/0 1). Basitarsus IV with a knobbed macroseta, 31 - 35 long.

\section{Deutonymph (male)}

(Figure 2) $(\mathrm{n}=1)$

The idiosomal and cheliceral characters are like those of female deutonymph however it can be distinguished by the number of setae in opisthogastric region (Fig. 2F) and the length of the dorsal shield (225). Opisthogastric cuticle with four pairs of setae (JV1,JV5, ZV1, ZV2) and four pairs of poroids. Length of opisthogastric setae: JV1 15, JV5 21, ZV1 11, ZV2 12, PA 11, PST 11.

Legs I-IV - Lengths: 235, 207, 198, 258, respectively. Genu IV with eight setae (2 2/1 2/0 1). Basitarsus IV with a knobbed macroseta, 30 long.

\section{Protonymph}

(Figure 3) $(n=3)$

Idiosoma oval. All idiosomal and leg setae smooth, except S2, S4, S5, Z4, Z5 and J5 barbed.

Dorsum (Fig. 3A) - Separate podonotal and opisthonotal shields; podonotal shield smooth, 122 - 127 long and 100 - 105 wide at level of $s 4$, with nine pairs of setae $(j 1, j 3, j 4, j 5, j 6, z 2, z 4, z 5, s 4)$, four pairs of poroids and solenostomes (prominent pores) absent. Opisthonotal shield reticulated, 78 80 long, 56 - 61 wide at level of $S 4$, with five pairs of serrated setae and four pairs of poroids; setae $J 2, s 6$, $S 2, r 3$ and $R 1$ on soft integument (Fig. 3A). Length of setae: j1 $14-15, j 318-19, j 412-14, j 512-13$, j6 19 - 20, J2 19, J5 10 - 11, z2 20, z4 27, z5 13, Z4 33 - 34, Z5 37, s4 19 - 21, s6 24, S2 26 - 27, s4 31, S5 33, r3 18-19, R1 20.
Venter (Fig. 3B) - Sternal shield smooth, with three pairs of setae subequal in length ( ST1-3: 17 18) and two pairs of poroids (iv1-iv2). Opisthogastric cuticle with three pairs of smooth setae (JV1, $J V 5, Z V 2)$ and five pair of poroids on small platelets. Anal opening surrounded with 3 setae (PA and PST). Length of opisthogastric setae: JV1 15, JV5 22, ZV2 10 - 11, PA12, PST 14.

Peritreme (Fig. 3A) - Vestigial; 15 - 18 long.

Chelicera (Fig. 3C) - Chelicera 85 long; fixed digit 15 long, with two teeth; pilus dentilis 2 long; movable digit $14-15$ long and with one tooth.

Legs I-IV (Figs. 3D-E) — Lengths: 210 - 215, 184 - 185, 170 - 175 and $220-225$, respectively. Genu II with six setae (1 2/0 2/0 1). Basitarsus IV with a knobbed macroseta, 31 long.

\section{Material examined}

All specimens are collected from leaves of pistachio trees, Pistacia atlantica Desf. (Anacardiaceae), Shiraz region $\left(29^{\circ} 25^{\prime} 41^{\prime \prime} \mathrm{N}, 53^{\circ} 13^{\prime} 37^{\prime \prime} \mathrm{E}\right.$ and altitude $1755 \mathrm{~m}$ a.s.l) (Fars province), Southwestern Iran, 25 vii 2016, by Samira Bakhshi. All specimens are deposited in the mite collection of the Acarology Laboratory of the Bu-Ali Sina University, Hamedan, Iran.

\section{DISCUSSION}

Paraseiulus is considered as a genus in the Phytoseiidae where sexual dimorphism occurs, with setae $z 6$ present in females but variable in males (Chant and McMurtry, 1994). However, in the present species $z 6$ is present in the males and also in the male and female deutonymphs; Setae $z 6$ are absent in the protonymph and obviously in the larva. Sexual dimorphism in the deutonymphs is typical for members of the Phytoseiidae (Arutunjan, 1970) [for example number of paired setae in the opisthogaster region in this species 6 (o) vs. $4\left(\sigma^{7}\right)$ and length of dorsal shield $\left.\left(q>\sigma^{x}\right)\right]$. Genu II has $8(2$ 2/1 $2 / 01$ ) setae in adults and deutonymphs but only 6 (1 2/0 2/0 1) in the protonymph. Furthermore, the macrosetae on basitarsus IV in immatures are knobbed in this species while pointed in adults. Comparison of characters of stages are presented in table 1 . 
TABlE 1: Comparison of characters of stages of Paraseiulus amacroporus Faraji et al., 2008. P.: Protonymph, D.: Deutonymph, A.: Adult.

\begin{tabular}{|c|c|c|c|c|c|}
\hline Ch. / Stage & P. & D. ( $(+)$ & D. $\left({ }^{\lambda}\right)$ & A. ( $(+)$ & A. $(\overbrace{}^{\Uparrow})$ \\
\hline L. d. s.* & $122-127,78-80$ & $265-270$ & 225 & $345-363$ & $260-280$ \\
\hline$j 1$ & + & + & + & + & + \\
\hline$j 3$ & + & + & + & + & + \\
\hline j4 & + & + & + & + & + \\
\hline$j 5$ & + & + & + & + & + \\
\hline$j 6$ & + & + & + & + & + \\
\hline$J 2$ & + & + & + & + & + \\
\hline J5 & + & + & + & + & + \\
\hline$z 2$ & + & + & + & + & + \\
\hline$z 3$ & - & + & + & + & + \\
\hline$z 4$ & + & + & + & + & + \\
\hline$z 5$ & + & + & + & + & + \\
\hline$z 6$ & - & + & + & + & + \\
\hline$Z 4$ & + & + & + & + & + \\
\hline$Z 5$ & + & + & + & + & + \\
\hline$s 4$ & + & + & + & + & + \\
\hline$s 6$ & + & + & + & + & + \\
\hline$s 2$ & + & + & + & + & + \\
\hline$S 4$ & + & + & + & + & + \\
\hline$S 5$ & + & + & + & + & + \\
\hline+3 & + & + & + & + & + \\
\hline$R 1$ & + & + & + & + & + \\
\hline$S T 1$ & + & + & + & + & + \\
\hline$S T 2$ & + & + & + & + & + \\
\hline$S T 3$ & + & + & + & + & + \\
\hline$S T 4$ & - & + & + & + & + \\
\hline$S T 5$ & - & + & + & + & + \\
\hline$J V 1$ & + & + & + & + & + \\
\hline$J V 4$ & - & + & - & + & - \\
\hline JV5 & + & + & + & + & + \\
\hline$Z V 1$ & - & + & + & + & - \\
\hline$Z V 2$ & + & + & + & + & + \\
\hline$Z V 3$ & - & + & - & + & - \\
\hline Setae $S 2-5, Z 4$ & Serrated & Serrated & Serrated & Smooth & Smooth \\
\hline Spermadactyl & - & - & - & - & + \\
\hline $\begin{array}{l}\text { Macrosetae on } \\
\text { basitarsus IV }\end{array}$ &,+ Knobbed & + , Knobbed &,+ Knobbed & + , Pointed & + , Pointed \\
\hline Genua II** & 6 & 8 & 8 & 8 & 8 \\
\hline
\end{tabular}

*: L. d. s. = Length of dorsal shield

**: Numbers of setae. 


\section{ACKNOWLEDGEMENTS}

This study was financially supported by the Bu-Ali Sina University, Hamedan, Iran.

\section{REFERENCES}

Arutunjan E.S. 1970 - Phytoseiid mites (Phytoseiidae) on agricultural crops in the Armenian SSR - Akademii Nauk Armyanskoi SSR, Otdelenie Biologicheskikh Nauk, Dissertatsii na Soiskanie Uchenoi Stepeni Candidata Biologrcheskikh Nauk, Zooliya, Armenia, 97:31 pp. [In Russian]

Athias-Henriot C. 1975 - Nouvelles notes sur les Amblyseiini. II. - Le relevé organotaxique de la face dorsale adulte (Gamasides, Protoadénique, Phytoseiidae) - Acarologia, 17: 20-29.

Berlese A. 1916 - Centuria prima di Acari nuovi - Redia, 12:19-66.

Chant D.A., McMurtry J.A. 1994 - A review of the subfamilies Phytoseiinae and Typhlodrominae (Acari: Phytoseiidae) - Internat. J. Acarol., 20(4): 223-310. doi:10.1080/01647959408684022

Chant D.A., McMurtry J.A. 2007 - Illustrated keys and diagnoses for the genera and subgenera of the Phytoseiidae of the world (Acarina: Mesostigmata) — Indira Publishing House, West Bloomfield, Michigan, USA, 220 pp.

Chant D.A., Yoshida-Shaul E. 1989 - Adult dorsal setal patterns in the family Phytoseiidae (Acari: Gamasina) - Internat. J. Acarol., 15(4): 219-232. doi:10.1080/01647958908683852

Chant D.A., Yoshida-Shaul E. 1991 - Adult ventral setal patterns in the family Phytoseiidae (Acari:Gamasina) — Internat. J. Acarol., 17(3): 187199. doi:10.1080/01647959108683906

Demite P.R., Moraes G.J.de., McMurtry J.A., Denmark H.A., Castilho R.C. 2017 - Phytoseiidae Database [Internet]. (09/03/2017) - Available at: www.lea.esalq.usp.br/phytoseiidae.

Faraji F., Jalaeian M., McMurtry J.A. 2008 - A new species of Paraseiulus Muma from Iran with a key to the known species (Acari: Mesostigmata: Phytoseiidae) - Zootaxa, 1770: 65-68.

Lindquist E.E., Evans G.O. 1965 - Taxonomic concepts in the Ascidae, with a modified setal nomenclature for the idiosoma of the Gamasina (Acarina: Mesostigmata) - Mem. Entomol. Soc. Can., 47: 1-59. doi:10.4039/entm9747fv

McMurtry J.A., De Moraes G.J., Sourassou N.F. 2013 Revision of the lifestyles of phytoseiid mites (Acari: Phytoseiidae) and implications for biological control strategies - Syst. Appl. Acarol., 18(4): 297-320. doi:10.11158/saa.18.4.1

Muma M.H. 1961- Subfamilies, genera, and species of Phytoseiidae (Acarina: Mesostigmata) - Bull. Flor. State Mus., Biol. Sci., 5(7): 267-302.

Rowell H.J., Chant D.A. 1979 - Observations on the ontogeny of setae in the family Phytoseiidae (Acarina: Gamasina) - Can. J. Zool., 57(3): 670-682. doi:10.1139/z79-080

Rowell H.J., Chant D.A., Hansell R.I.C. 1978 - The determination of setal homologies and setal patterns on the dorsal shield in the family Phytoseiidae (Acarina: Mesostigmata) — Can. Entomol., 110: 859-876. doi:10.4039/Ent110859-8

Wainstein B.A. 1962 - Revision du genre Typhlodromus Scheuten, 1857 et systematique de la famille des Phytoseiidae (Berlese, 1916) (Acarina: Parasitiformes) Acarologia, 4:5-30.

Wainstein B.A. 1976 - A new tribe of the family Phytoseiidae (Parasitiformes) — Zool. Zhurnal., 55(5):696-700. [In Russian].

\section{COPYRIGHT}

$(\mathrm{cc}$ )EY-No-ND Asali Fayaz B. et al. Acarologia is under free license. This open-access article is distributed under the terms of the Creative Commons-BY-NC-ND which permits unrestricted non-commercial use, distribution, and reproduction in any medium, provided the original author and source are credited. 